\title{
Trained and dedicated staff appears to be the main factor in decreasing anxiety and improving overall satisfaction during urodynamic testing: A prospective, randomized trial
}

\author{
Rose Khavari, MD; Cindy Gu, BSc,; Anastasia C. Tran, BA,; Robert Chan, $M D^{1}$ \\ 'Houston Methodist Hospital, Department of Urology, Houston, TX, United States; ${ }^{2}$ Vanderbilt University, Nashiville, TN, United States; ${ }^{3 T e x a s}$ A\&M Medical School, Bryan, TX, United States
}

Cite as: Can Urol Assoc J 2016;10(5-6):187-90. hitp://dx.doi.org/10.5489/cuaj.3421

See related commentary on page 191.

\section{Abstract}

Introduction: We sought to determine whether listening to patientselected music during urodynamic study (UDS) reduced pain and anxiety while increasing overall patient satisfaction and willingness to repeat the procedure.

Methods: Fifty-one (51) patients who underwent UDS from March to July 2014 were randomized into two groups: Group 1 with patient-selected music during the procedure $(n=27)$ and Group 2 without music $(n=24)$. Standard multichannel filling cystometry was performed. Anxiety was self-assessed using the State Trait Anxiety Inventory, while overall pain, satisfaction, and willingness to undergo the procedure again were self-measured using a visual analogue scale.

Results: Demographic characteristics and reasons for testing were similar between the two groups. The state score for Groups 1 and 2 were 27.04 and 29.5 , respectively $(p=0.3225)$ and 31.78 and 33.86 , respectively $(p=0.4970)$ for the trait score. The mean pain scores were 1.04 and 1.57 , respectively $(p=0.2047)$; the mean satisfaction scores were 0.65 and 0.52 , respectively $(p=0.8169)$; and the scores for willingness to undergo the procedure again were 0.77 and 0.74 , respectively $(p=0.9442)$. While there were no significant differences between the two groups in anxiety and satisfaction scores, pain, and willingness to undergo the procedure again, both groups commented on the nurse as the most important factor in their overall comfort.

Conclusions: Music during UDS did not appear to lower pain and anxiety, nor increase overall satisfaction and willingness to repeat the procedure. The most important aspect in alleviating patients' pain and anxiety was the person actually performing the testing, highlighting the importance of having trained and dedicated staff.

\section{Introduction}

Urodynamic study (UDS) is a functional and interactive diagnostic study used to evaluate the filling phase and the voiding phase of the micturition cycle. This technique is often combined with concurrent fluoroscopy to reveal the anatomical integrity of the lower urinary tract in complex cases or in patients with neurogenic bladder. This study is usually performed in an office setting with the patient awake and in a sitting position with multiple perineal, vesical, and rectal sensors and catheters attached to the patient. Real-time sensations and events, such as Valsalva leaks, are documented (by the nurse and/or physician present in the room) in an effort to reproduce the patient's symptoms. ${ }^{1}$ Oftentimes, invasive urodynamic testing is considered a cumbersome, uncomfortable, fear-inducing process, which is associated with considerable morbidity and complications, especially in men with bladder outlet obstruction. ${ }^{2}$ Therefore, new methods for easing this patient burden are needed to keep abreast of increased testing needs.

Various pharmacologic and non-pharmacologic methods have been attempted in an effort to discern the most successful and cost-effective combination for easing the testing burden. Sedatives and analgesics have demonstrated only a modest reduction in patient discomfort and pain. ${ }^{3}$ Nonpharmacologic methods, such as distraction with pleasant memories and cutaneous stimulation, especially with cold sensations, have proven to be effective in alleviating pain and anxiety. ${ }^{4}$ Music, with its long history in medicine as a method of relaxation, has shown a high degree of potential for assisting patients undergoing UDS. Both low-risk and inexpensive, music has already proven successful in alleviating patient anxiety in stressful environments and surroundings. ${ }^{5,6}$ Furthermore, music has been shown to markedly reduce self-reported pain and anxiety, the need for sedative medications, and the amount of patient-controlled analgesics during colonoscopies. ${ }^{7-10}$ Recent studies have 
Khavari et al.

also specifically demonstrated reductions in pain, anxiety, and patient dissatisfaction during other in-office urological procedures, such as cystoscopies. ${ }^{11}$

While the use of music as a method for alleviating pain and anxiety has been well-studied in gastroenterologic procedures, comparatively little work has been performed in the setting of UDS, despite the increasing need. Therefore, we decided to compare the efficacy of listening to self-selected music as a pain and anxiety-reducing technique during urodynamic evaluation.

\section{Methods}

\section{Patient and urodynamic procedure}

From March 2014 to July 2014, 81 patients were screened at our teaching institution. Fifty-one (51) male and female patients undergoing urodynamic testing were recruited for this study at Methodist Hospital in Houston, TX, and block randomized into two groups: 27 patients in Group 1 listened to self-selected music via a headset, while 24 patients in Group 2 wore a headset, but did not listen to music. All patients were identified and selected by the same urodynamics nurse on the day of the urodynamic evaluation. We included any patient undergoing urodynamic evaluation with the mental capacity to undergo the distraction task and fill out a survey after the procedure. Persons speaking any language or of any ethnicity would be enrolled. Our exclusion criteria precluded enrollment of any patient mentally unable to meaningfully undergo a distraction task, i.e., with severe mental retardation. All procedures were performed by the same team of physicians, who explained each step of the process as it occurred.

All patients were evaluated in the sitting position with standard uroflow, Laborie multichannel filling cystometry, and pressure flow voiding with no additional manipulations or studies performed. Uroflow was performed first with additional placement of a vesical and rectal catheter (for intraabdominal pressure) for cystometric evaluation. A fill rate of $50 \mathrm{~mL} /$ minute was used and first sensation, desire, strong desire, Valsalva leak point pressures, and maximum capacity were measured. Each patient was also asked to cough and Valsalva at $150 \mathrm{~mL}, 300 \mathrm{~mL}$, and at capacity. A power calculation performed expecting standard deviation in visual analogue scale (VAS) of 1.5 with a power level of 0.9 and a significance type- 1 error of 0.01 suggested that each study group required 24 participants for a total sample of 48 .

\section{Analysis of pain and anxiety}

We evaluated anxiety using the State Trait Anxiety Inventory, a validated self-assessed anxiety measure using two sub- scales each containing 20 multiple-choice questions. The total anxiety inventory ranges from a score of 20-80, with higher scores indicating greater anxiety. Patients also selfreported their pain, overall satisfaction, and willingness to undergo the procedure again using the VAS scored from 0-10. We determined statistical significance using an independent t-test with statistical significance assessed for $\mathrm{p}<0.05$.

\section{Results}

Demographic characteristics (age, gender, pattern of incontinence) and reasons for the study were statistically similar between the two groups (Table 1). CONSORT flow diagram was used to show randomization algorithm (Fig. 1). The anxiety scores assessed in Group 1 and 2 after the urodynamic testing did not differ significantly from each other. The state score for Groups 1 and 2 were 27.04 and 29.50, respectively ( $\mathrm{p}=0.3225)$ and 31.78 and 33.88 , respectively $(p=0.4970)$ for the trait score. There was also no significant difference between Group 1 and 2 in the mean pain and satisfaction scores and willingness to undergo the procedure again. The mean pain scores were 1.04 and 1.57, respectively $(p=0.2047)$; the mean satisfaction scores were 0.65 and 0.52 , respectively $(p=0.8169)$; and the scores for willingness to undergo the procedure again were 0.77 and 0.74 , respectively $(p=0.9442)$.

\section{Discussion}

As the U.S. elderly population continues to expand at a marked rate, the need for urodynamic testing and evaluation increases in men and women above age 65. Evaluation of trends in use of the cystometrogram in the U.S. suggest

Table 1. Comparison of subject demographics between Group 1 and Group 2 with associated p values and as $\mathbf{n}(\%)$

\begin{tabular}{lccc}
\hline Demographic & $\begin{array}{c}\text { Group } \mathbf{1} \\
\mathbf{n = 2 7}\end{array}$ & $\begin{array}{c}\text { Group } 2 \\
\mathbf{n = 2 4}\end{array}$ & p value \\
\hline Mean age $( \pm$ SD) (years) & $\begin{array}{c}51.74 \\
( \pm 15.3)\end{array}$ & $\begin{array}{c}53.67 \\
( \pm 18.2)\end{array}$ & 0.6834 \\
Gender & & & \\
$\quad$ Male & $4(15)$ & $4(17)$ & 0.856 \\
$\quad$ Female & $23(85)$ & $20(83)$ & \\
History of & & & \\
$\quad$ Neurogenic bladder & $10(37)$ & $7(24)$ & 0.552 \\
$\quad$ Catheter use & $10(37)$ & $5(21)$ & 0.205 \\
$\quad$ Anxiety & $8(30)$ & $4(17)$ & 0.276 \\
$\quad$ Depression & $8(30)$ & $9(38)$ & 0.3542 \\
Stress urinary incontinence & $9(33)$ & $10(42)$ & 0.539 \\
$\begin{array}{l}\text { Urgency or urge urinary } \\
\text { incontinence }\end{array}$ & $16(59)$ & $13(51)$ & 0.714 \\
\hline
\end{tabular}




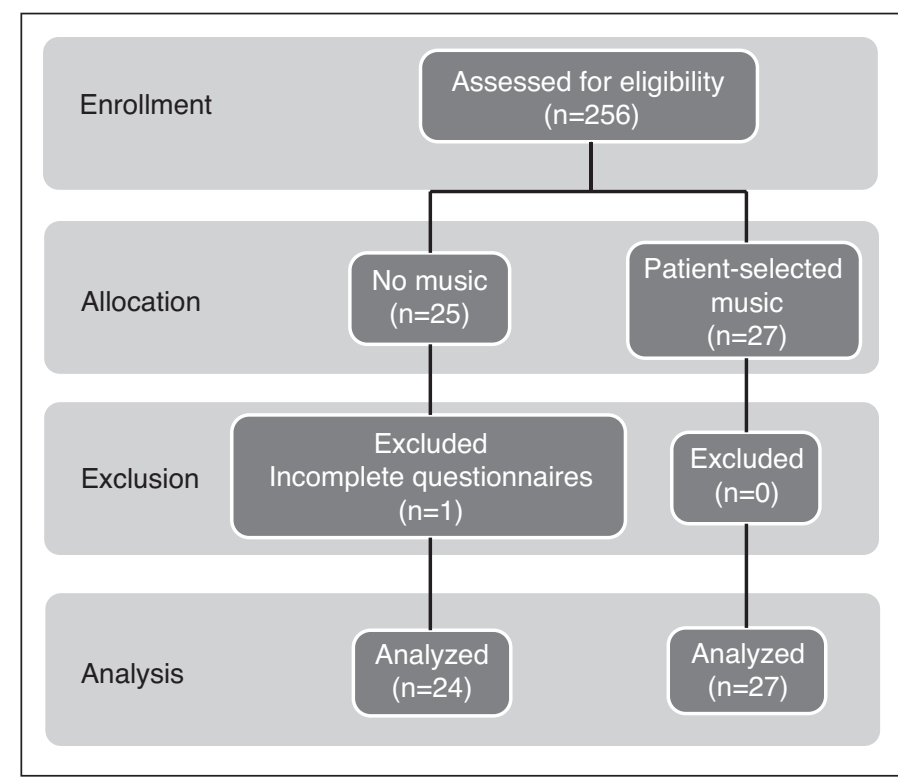

Fig. 1. Flowchart of patient accruement, allocation, and analysis.

increases with age, peaking at age 85 with a rate of 77.7 per 10000 person-years in men and at age 76 in women with a rate of 86.6/10,000 person-years. ${ }^{12,13}$ The pain, discomfort, and anxiety associated with urodynamic evaluation have long been a barrier to increasing testing levels and compliance within the general population and especially within the growing elderly population. Indeed, while the perceived pain and discomfort of urodynamic testing often outweigh the actual pain and discomfort of the procedure, apprehension still serves as a strong impediment to compliance. . $^{14,15}$ This uneasiness, along with the general anxiety produced by sedation analgesia in a patient who is awake and must remain immobile for an extended period, can greatly augment the perception of pain. ${ }^{16}$ Effective, cost-conscious, and easily implemented analgesic and anxiolytic methods are thus needed for use during urodynamic evaluation.

Music has long been an effective method, with a proven history of alleviating pain during a procedure and even while awaiting a procedure. ${ }^{17}$ It has continually demonstrated efficacy in easing pain and anxiety in a wide variety of environments and various potentially stressful procedures. ${ }^{18,19}$ Indeed, combined audio and visual distraction techniques have demonstrated strong utility in lowering pain and anxiety levels through decreased salivary cortisol levels. ${ }^{20}$ Despite this success, music as an analgesic and anxiolytic method has only recently been investigated in urodynamic evaluation, ${ }^{21}$ where no improved benefit was seen in patients who listened to music or viewed educational videos compared in addition to routine care.

Contrary to our expectations, we did not observe a significant decrease in pain perception or anxiety in patients listening to music during urodynamic testing. While previous research had demonstrated a significant difference in pain levels and anxiety in patients listening to music during cystoscopic procedures, our study and another recent study ${ }^{21}$ did not demonstrate similar levels of patient satisfaction. Our study was low-powered and limited because of the relatively small sample size of 27 and 25 patients in Groups 1 and 2, respectively. Perhaps, had we been able to recruit a larger group of patients, we might have seen a significant difference in pain and anxiety more in accordance with previous studies.

One of the key factors that separates our study from the recent report by Solomon et al is that rather than using instrumental music preselected by the investigator, our patients were asked to choose the genre and type of music they preferred to listen to, with the hope that patient would be more engaged and at ease. ${ }^{22}$ The Solomon's group recruited only female patients and had a more urogynecology-focused patient population with prolapse, stress urinary incontinence, and urge incontinence vs. our group of patients, who represented more of a wide range of patients, including males and patients with neurogenic bladder.

Another confounding factor would be to use VAS to evaluate pain during cystoscopy and UDS. Arguably, pain may not be the best outcome to measure the discomfort during urodynamic testing since many may consider UDS a nonpainful procedure. Other outcome measures, such as the rate of spontaneous voiding in each group, could have been documented and added as another surrogate for evaluating comfort during UDS.

In addition, while the impact of music did not prove significant, both groups specifically commented on the nurse performing the urodynamic testing as the most important factor in their overall comfort and level of anxiety. Her warm demeanor and, especially, her skillful and informative explanation of each step of the testing process were cited as the greatest sources of relaxation and comfort. For our patients, regardless of any other environmental factors, such as music, the state of the procedure room, or quality of the machinery, the most important aspect in alleviating patient pain and anxiety was the person actually performing the urodynamic testing. Thus, our study underscores the importance of having trained and dedicated staff in order to best address patient concerns about pain and anxiety.

\section{Conclusion}

In our study, patient-selected music during UDS did not appear to lower pain and anxiety, nor increase overall satisfaction and willingness to repeat the procedure. Although our study was not designed to determine the value of the UDS personnel, our patients' reported that the most important factor in alleviating their pain and anxiety was the person actually performing the testing, highlighting the importance of having trained and dedicated staff. 
Khavari et al.

Competing interests: Dr. Khavari has participated in clinical trials for Allergan. The remaining authors declare no competing personal or financial interests.

Acknowledgement: Rose Khavari is a scholar supported in part by NIH grant K12 DK0083014, the Multidisciplinary K12 Urologic Research (KURe) Career Development Program to Dolores J Lamb (DJL) from the National Institute of Diabetes and Digestive and Kidney Diseases (NIDDK), National Institutes of Health.

This paper has been peer-reviewed.

\section{References}

1. Raz 0, Tse V, Chan L. Urodynamic testing: Physiological background, setting-up, calibration and artefacts. BJU Int 2014;114: 22-8. http://dx.doi.org/10.1111/bju.12633

2. Klingler HC, MadersbacherS, DjavanB, et al. Morbidity of the evaluation of the lower urinary tract with transurethral multichannel pressure-flow studies. J Urol 1998;159:191-4. http://dx.doi.org/10.1016/ S0022-5347(01)64054-0

3. Song YS, Song ES, Kim KJ, et al. Midazolam anesthesia during rigid and flexible cystoscopy. Urol Res 2007;35:139-42. http://dx.doi.org/10.1007/s00240-007-0091-7

4. McCaffery M. Nursing approaches to nonpharmacological pain control. Int J Nurs Stud 990;27:1-5. http:// dx.doi.org/10.1016/0020-7489(90)90018-E

5. Krout RE. The effects of single-session music therapy interventions on the observed and self-reported levels of pain control, physical comfort, and relaxation of hospice patients. Am J Hosp Palliat Care 2001;18:38390. http://dx.doi.org/10.1177/104990910101800607

6. Nilsson U, Rawal N, Enqvist B, et al. Analgesia following music and therapeutic suggestions in the PACU in ambulatory surgery: A randomized, controlled trial. Acta Anaesthesiol Scand 2003;47:278-83. http:// dx.doi.org/10.1034/i.1399-6576.2003.00064.x

7. Harikumar R, Raj M, Paul A, et al. Listening to music decreases need for sedative medication during colonoscopy: A randomized, controlled trial. Indian I Gastroenterol 2006;25:3-5.

8. Lee DW, Chan KW, Poon CM, et al. Relaxation music decreases the dose of patient-controlled sedation during colonoscopy: A prospective, randomized, controlled trial. Gastrointest Endosc 2002;55:33-6. http:// dx.doi.org/10.1067/mge.2002.120387

9. Lopez-Cepero Andrada JM, Amaya Vidal A, Castro Aguilar-Tablada T, et al. Anxiety during the performance of colonoscopies: Modification using music therapy. Eur J Gastroenterol Hepatol 2004;16:1381-6. http:// dx.doi.org/10.1097/00042737-200412000-00024
10. Ovayolu N, Ucan 0 , Pehlivan S, et al. Listening to Turkish classical music decreases patients' anxiety, pain, dissatisfaction and the dose of sedative and analgesic drugs during colonoscopy: A prospective, randomized, controlled trial. World J Gastroenterol 2006;12:7532-6. http://dx.doi.org/10.3748/wig.v12.i46.7532

11. Yeo JK, Cho DY, Oh MM, et al. Listening to music during cystoscopy decreases anxiety, pain, and dissatisfaction in patients: A pilot randomized, controlled trial. J Endourol 2013;27:459-62 . http://dx.doi. org/10.1089/end.2012.0222

12. Conover MM, Jonsson Funk M, Kinlaw AC, et al. Trends and patterns of urodynamic studies in U.S. males, 2000-2012. PLoS One 2015;10:e0133657. http://dx.doi.org/10.1371/journal.pone.0133657

13. Conover MM, Jonsson Funk M, Kinlaw AC, et al. Trends and patterns of urodynamic studies in U.S. women, 2000-2012. Obstet Gynecol 2015;125:559-65. http://dx.doi.org/10.1097/ AOG.0000000000000641

14. Yerlikaya $G$, Laml T, Elenskaia $K$, et al. Pain perception during outpatient cystoscopy: A prospective, controlled study. Eur J Obstet Gynecol Reprod Biol 2014;173:101-5. http://dx.doi.org/10.1016/i. ejogrb.2013.11.007

15. Yiou R, Audureau E, Loche CM, et al. Comprehensive evaluation of embarrassment and pain associated with invasive urodynamics. Neurourol Urodyn 2015; 34:156-60. http://dx.doi.org/10.1002/nau.22521

16. Welsh J. Reducing patient stress in theatre. Alison Bell Memorial Award. Br J Perioper Nurs 2000;10:321-4.

17. Biddiss $E$, Knibbe TJ, McPherson A. The effectiveness of interventions aimed at reducing anxiety in healthcare waiting spaces: A systematic review of randomized and nonrandomized trials. Anesth Analg 2014;119:433-48. http://dx.doi.org/10.1213/ANE.0000000000000294

18. Mandel SE, Davis BA, Secic M. Effects of music therapy on patient satisfaction and health-related quality of life of hospital inpatients. Hosp Top 2014;92: 28-35. http://dx.doi.org/10.1080/00185868.2 014.906830

19. Tsai HF, Chen YR, Chung MH, et al. Effectiveness of music intervention in ameliorating cancer patients' anxiety, depression, pain, and fatigue: A meta-analysis. Cancer Nurs 2014;37:E35-50. http://dx.doi. org/10.1097/NCC.0000000000000116

20. Ha YO, Kim HS. The effects of audiovisual distraction on children's pain during laceration repair. Int J Nurs Prac 2013;19 Suppl 3:20-7. http://dx.doi.org/10.1111/ijn.12165

21. Solomon ER, Ridgeway B. Interventions to decrease pain and anxiety in patients undergoing urodynamic testing: A randomized controlled trial. Neurourol Urodyn 2015; Jul 30. [Epub ahead of print]. http:// dx.doi.org/10.1002/nau.22840

22. Hogan TJ, Silverman M J. Coping-infused dialogue through patient-preferred live music: A medical music therapy protocol and randomized pilot study for hospitalized organ transplant patients. J Music Ther 2015:52:420-36. http://dx.doi.org/10.1093/imt/thv008

Correspondence: Dr. Rose Khavari, Houston Methodist Hospital, Department of Urology, Houston, TX, United States; rkhavari@houstonmethodist.org 